\title{
Antibiotic sensitivity pattern in culture positive typhoid fever cases isolated at Patan hospital
}

\author{
Sanjaya Kumar Shrestha ${ }^{1}$, Shova Basnet ${ }^{2}$ \\ ${ }^{I}$ Department of Internal Medicine, Patan Academy of Health Sciences, Lalitpur, Nepal \\ ${ }^{2}$ Department of Pediatrics, Patan Academy of Health Sciences, Lalitpur, Nepal
}

\author{
Keywords: \\ Antimicrobial Sensitivity \\ Test; \\ Chloramphenicol; \\ Ciprofloxacin; \\ Ceftriaxone; \\ Enteric fever
}

\begin{abstract}
Background: Enteric fever is one of the most common systemic infections of developing countries like Nepal. The changing trend of antibiotic susceptibility and the increasing rate of resistance to the commonly used antibiotics has been of great concern in the proper treatment and prevention of this disease. This study aims to investigate the current antibiotic susceptibility pattern of Salmonella typhi and paratyphi.
\end{abstract}

Materials and Methods: This study was carried out at Patan hospital of Lalitpur, Nepal over a period of Eight months. Blood culture samples were collected from suspected patients presenting to different departments of the hospital and tested microbiologically by standard procedure. Antibiotic susceptibility test was performed by Kirby Bauer Disc Diffusion method and results were interpreted by National Committee for Clinical Laboratory (NCCLS) guidelines.

Results: 130 blood culture samples were isolated as Salmonella species. Out of these, 103 (79.2\%) cases were S typhi and 27 (20.8\%) were S paratyphi A. Isolates were mainly from adult age group. Regarding the antibiotic susceptibility pattern, the sensitivity to Ciprofloxacin and Ofloxacin were 5.4\% each whereas the sensitivity to Chloramphenicol, Cotrimoxazole, Gentamycin and Azithromycin were 100\%. Nalidixic Acid Resistance Salmonella typhi strains were 87.7\%.

Conclusion: A high degree of variability is seen in antimicrobial sensitivity pattern with very high degree of sensitivity to the historically used antibiotics like Chloramphenicol and Cotrimoxazole. Sensitivity to quinolones was seen to be very low, which were used widely in the last two decades. .

Erratum: The antibiotics lists in Table 1 of this article were erroneous. The corrected antibiotic lists are presented in this erratum. The results and discussion has been modified accordingly. (25 August 2019)

\section{Correspondence:}

Dr. Sanjaya Kumar Shrestha

Department of Medicine,

Patan Academy of Health Science, Lalitpur, Nepal

ORCID ID: 0000-0003-2860-6293

Email: sanjayakumar70@gmail.com

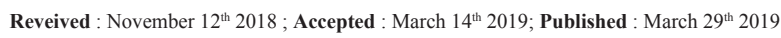

Citation: Shrestha SK, Basnet S. Antibiotic sensitivity pattern in culture positive typhoid fever cases isolated at Patan hospital. J Pathol Nep 2019;9:1450-2. DOI 10.3126/jpn.v9i1.23348

Copyright: This is an open-access article distributed under the terms of the Creative Commons Attribution 4.0 International License, which permits unrestricted use, distribution, and reproduction in any medium, provided the original author and source are credited.

\section{INTRODUCTION}

Typhoid fever is one of the commonest systemic infections of public health importance in the developing countries. ${ }^{1}$ It is caused by Salmonella enterica subspecies enterica serovars typhi (S typhi) and paratyphi (S paratyphi).The spread of the disease is mainly by the use of substandard water supply, sanitation and contaminated foods. Globally, the annual incidence of typhoid fever is 0.3 percent. $^{2} \mathrm{Nepal}$ is regarded as the capital city of typhoid fever and frequent outbreaks have been reported in the past few years. ${ }^{3}$ After a few days of bacteremia, the bacilli localize mainly in the lymphoid tissue of the small intestine, resulting in typical 
Table 1: Antibiotic sensitivity pattern of culture-positive Salmonella $(n=130)$

\begin{tabular}{lcc}
\hline Antibiotics & Sensitive (n) & Resistant $\mathbf{n}(\%)$ \\
\hline Cefotaxime & $107(82.3)$ & $23(17.7)$ \\
Ciprofloxacin & $7(5.4)$ & $123(94.6)$ \\
\hline Chloramphernicol & $130(100)$ & 0 \\
Cotrimoxazole & $130(100)$ & 0 \\
Genramycin & $130(100)$ & 0 \\
Nalidixic Acid & $16(12.3)$ & $114(87.7)$ \\
\hline Ofloxacin & $7(5.4)$ & $123(94.6)$ \\
\hline Azithromycin & $130(100)$ & 0
\end{tabular}

lesions in Payer's patches and follicles. These lesions swell at first, then ulcerate and usually heal. After clinical recovery, about $5 \%$ of the patient's become chronic carriers and pass the bacteria intermittently in stool and rarely in urine. ${ }^{4}$

The clinical presentation, laboratory findings, antibiotic sensitivity pattern of organisms and the clinical response of the illness to the antibiotics differ from one country to another and within the same country in due course of time. The persistence of the organisms in human body in carrier state despite the full course of treatment and its reactivity during the immunodeficiency period is the reason why most of the antibiotic resistance incidence have occurred. ${ }^{5}$ In southern Viet Nam, multidrug resistance in S. typhi had become established by late 1992 and early 1993. ${ }^{6-8}$ These multidrug-resistant $\mathrm{S}$. typhi isolates were resistant to the usual first-line antibiotics, chloramphenicol, ampicillin, and co-trimoxazole, but remained fully susceptible to the fluoroquinolones and third-generation cephalosporins.

This is a study of the Salmonella enterica species grown in human blood and the resistance pattern of the organisms to the commonly used antibiotics in a tertiary care setting.

\section{MATERIALS AND METHODS}

A retrospective, eight-month duration, from Feb 2016 to Sep 2016, record-based analysis was carried out for all the blood and bone-marrow culture proven typhoid cases from the registry of Patan Hospital, Lalitpur. Due permission was sought from the hospital authorities to access the records. Patients of all the age groups were enrolled during the study. All strains of salmonella were serotyped at the laboratory of Patan hospital. All blood cultures were incubated at $37^{\circ} \mathrm{C}$ for at least 7 days. Salmonella strains were tested for their sensitivity to eight anti-microbial agents by the disc diffusion method using Mueller Hinton agar according to the Bauer-Kirby method. ${ }^{9}$ The strains were identified as sensitive, intermediate or resistant as per the diameter of zone of inhibition. The intermediate sensitive strains have been taken as resistant strains for the analysis in this study..

\section{RESULTS}

There were altogether 130 positive blood cultures for Salmonella typhi in the eight-month duration. Out of the total, there were $103(79.2 \%)$ of Salmonella typhi and $27(20.8 \%)$ were Salmonella paratyphi A. Out of the 130 culture-positive S. typhi infections, 114 (87.7\%) were Nalidixic Acid Resistant S. typhi (NARST) strain (Table 1). The sensitivity pattern of the Salmonella isolated is shown in the table 1. All the Salmonella isolates were found to be sensitive to Chloramphenicol, Cotrimoxazole, Gentamycin and Azithromycin.

\section{DISCUSSION}

The threat to human health posed by growth of antibioticresistant bacterial pathogen is of growing concern in medical practice. Drug resistance in typhoid fever is considered to be important factor in the morbidity and mortality of this disease. The emergence of multidrug-resistant enteric fever led to use of fluoroquinolones or the third generation cephalosporins as the first-line therapy during the 1990s. Unfortunately, broad-spectrum antibacterial activity, affordability and easy availability led to their indiscriminate use in human medicine. Furthermore, NARST with reduced susceptibility to ciprofloxacin (MIC 50 of $0.125-1 \mathrm{mg} / \mathrm{ml}$ ) causing clinical failure emerged worldwide and became endemic in the Indian subcontinent. ${ }^{10,11}$ Chloramphenicol, discovered in 1947, was the first antibiotic successfully used in the treatment of typhoid fever. In view of the bone marrow suppression by this drug in some patients, this drug became less popular and other drugs like amoxicillin and cotrimoxazole were also successfully used to treat typhoid fever. However, indiscriminate use of drugs and acquisition of plasmid mediated $\mathrm{R}$ factor led to the development of resistance of S. typhi against some of the drugs. ${ }^{12}$ However, our study shows quite a surprising result regarding chloramphenicol and cotrimoxazole resistance pattern, the drugs that were used in the early days of typhoid treatment. The sensitivity to the early-days antibiotics, especially Chloramphenicol and Cotrimoxazole were 100\% which are in accordance with some other studies. ${ }^{13,14}$ Our findings show a remarkable reversal in the resistance pattern of Salmonella typhi. Salmonella strains which were almost $100 \%$ sensitive to fluoroquinolones a decade or two ago are now seen to have a very low degree of sensitivity to these antibiotics, $5.4 \%$ for both Ciprofloxacin and Ofloxacin in this study. NARST strains, which may show antibiotic susceptibility to fluoroquinolones in vitro are considered to be resistant to fluoroquinolones in vivo, ${ }^{15}$ which may further reduce the actual sensitivity of these fluoroquinolones. Sensitivity to third generation Cephalosporins has also gone down, $82 \%$ for Cefotaxime in this study. However, Azithromycin shows $100 \%$ sensitivity. 


\section{CONCLUSION}

The prevalence of fluoroquinolone resistance salmonella species is very high, $94.6 \%$ for both Ciprofloxacin and Ofloxacin in our study. Taking into account the NARST strain of $87.7 \%$ in our study it can be deduced that even higher percentage of resistance would be shown by these strains in vivo, because even those strains that are sensitive to fluoroquinolones in vitro would be resistant in vivo when they are resistant to Nalidixic acid. However, historically used antibiotics like Chloramphenicol and Cotrimoxazole, and recently used antibiotics like Azithromycin show 100\% sensitivity.

\section{REFERENCES}

1. Crump JA, Luby SP, Mintz ED. 'The global burden of typhoid fever.' Bull World Health Organ. 2004;82:346-53. Crossref

2. Ivanoff B. Typhoid fever: global situation and WHO recommendation, southeast Asian J. Trop Med Public Health 1995: 1-7

3. Karkey A, Aryjal A, Basnyat B, Baker S. Kathmandu, Nepal: still an enteric fever capital of the world'. J Infect Dev Ctries. 2008;2(6):4615. Crossref

4. Walker B, Colledge NR, Ralston S, Penman I. Davidson's principles and practice of medicine. 22nd ed. Churchill Livingstone, London; 2014.1392p.

5. Merrell DS, Falkow S. 'Frontal and stealth attack strategies in microbial pathogenesis.' Nature. 2004;430:250-6. Crossref

6. Hien TT, Duong NM, Ha HD, et al. A randomized comparative study of fleroxacin and ceftriaxone in enteric fever. Trans R Soc Trop Med Hyg 1994;88:464-5. Crossref
7. Smith MD, Duong NM, Hoa NTT, et al. Comparison of ofloxacin and ceftriaxone for short-course treatment of enteric fever. Antimicrob Agents Chemother 1994;38:1716-20. Crossref

8. Hien TT, Bethell DB, Hoa NTT, et al. Short course of ofloxacin for treatment of multidrug-resistant typhoid. Clin Infect Dis 1995;20:917-23. Crossref

9. Bauer AW, Kirby WM, Sherris JC, Turck M. Antibiotic susceptibility testing by a standardized single disk method. Am J Clin Pathol. 1966;45:493-6. Crossref

10. Threlfall EJ, Ward LR, Skinner JA, Smith HR, Lacey S. Ciprofloxacin-resistant Salmonella typhi and treatment failure. Lancet 1999;353:1590-1. Crossref

11. Capoor MR, Nair D, Aggarwal P, Mathys V, Dehem M, Bifani PJ. Salmonella enterica serovar typhi: molecular analysis of strains with decreased susceptibility and resistant to ciprofloxacin in India from 2001-2003. Braz J Infect Dis. 2007;11:423-5. Crossref

12. Agarwal KC, PanHotra BR, Mahanta J. 'Typhoid fever due to chloramphenicol resistant S.typhi associated with 'r' plasmid'. Indian J Med Res 1981;73:484-8. Crossref

13. Pandit V, Kumar A, Kulkarni MM, Pattan shetty SM, Charmine C, Kamath S. Study of clinical profile and antibiotic sensitivity in paratyphoid fever cases admitted at teaching hospital in South India. J Family Med Prim Care. 2012;1:118-21. Crossref

14. Threlfall EJ. Ward LR. Decreased susceptibility to ciprofloxacin in Salmonella enterica serotype typhi, United Kingdom. Emerg Infect Dis. 2001;7:448-50. Crossref

15. Wain J, Hoa NTT, Chinh NT et al. Quinolone-Resistant Salmonella typhi in Viet Nam: Molecular Basis of Resistance and Clinical Response to Treatment. Clin Infect Dis. 1997;25:1404-10. $\underline{\text { Crossref }}$ 